could concentrate on this subject, they would do industry a real service, for nearly all industrial operations such as punching, shearing, forging, milling, spinning, and, of course, the turning of metals, are plastic flow phenomena.

During experiments I carried out with heavy lathes in 1908 for the purpose of finding the most economical high-speed steel to use, I encountered some chips which were not only straight but actually presented concavity to the tool face, and I have one of these chips now. They were produced at very high speed on steel, and are mentioned in the discussion of a paper read before the Siemens' Stafford Engineering Society in 1908 (Proc., vol. I, p. 93), on "The Plastic Deformation of Solids."

Brewster's beautiful photo-elastic method and Professor Coker's important applications of it enable the stresses during elastic strain of the tool and material in the region A to be computed, but Taylor, in the work cited, has shown how a tool should be forged and supported on the saddle to give it maximum life and maximum strength.

Unfortunately for engineering industry in this country, nearly all lathes are built with the vertical space between the upper surface of the tool rest and the line of centres far too small to enable Taylor's important conclusions to be put into practice.

Alan Pollard.

Imperial College of Science and Technology, November 29.

I GATHER from Mr. H. S. Rowell's letter published in NATURE for December 9 that, while interested in the subject of the flow of metals in shavings, he is not altogether familiar with the work that has already been done on the subject. In a comprehensive "Mémoire sur le rabotage des métaux" (which cannot be so well known as I have hitherto believed) published more than forty years ago, M. H. Tresca investigated the question of the curling of shavings, both experimentally and mathematically, the actual flow of the metal (expressed by a coefficient de réduction) being especially selected for study under very varied conditions. The following quotation indicates only part of the scope of the work: "Ces phénomènes sont aussi ceux dans lesquels, pour la première fois, les métaux les plus durs, tels que l'acier, le fer, se comportent en réalité comme le plomb, comme le savon, comme le cire, nous dirions presque comme les liquides, tant est complet le rapprochement que l'on doit faire entre les rides de nos différents copeaux et de véritables vagues de métal."

The memoir is published as one of the "Mémoires présentés par divers savants à l'Académie des Sciences de l'Institut de France," tome xxvii., I883. Those familiar already with the beauty of the results obtained will pardon this effort to direct the attention of others to the work.

Artillery College, Woolwich,

$$
\text { E. N. Da C. Andrade. }
$$

December I I.

\section{The Secondary Spectrum of Hydrogen.}

SINCE the negatively charged hydrogen atom is known to exist, from work on positive rays, it seemed likely that Silberstein's particular solution of the three-body problem, applied by him to the case of neutral helium (Astrophys. Jour., September 1922) should also be applicable in this case. Consequently the formula used by him was modified so as to apply to hydrogen (charge $\mathrm{E}$ instead of $2 \mathrm{E}$, and hence $\mathrm{N}$ instead of $4 \mathrm{~N}$ ), and also a small but important correc- tion was made to the value of $\mathrm{N}$ so as to take account of the fact that with two electrons instead of one, the correction to the mass of the electron for the finite mass of the nucleus is no longer the same.

It was assumed as a first approximation that the electrons would be arranged antipodally, and consequently the forces would be again central. So Curtis's value of $\mathrm{N}$ for hydrogen was corrected so as to apply to a nucleus of infinite mass :

$$
\mathrm{N}_{\infty}=\mathrm{N}_{\mathrm{H}}\left(\mathrm{I}+\frac{m}{\mathrm{M}}\right) \text {. }
$$

Frequencies were then calculated from the formula

$$
\nu=\mathrm{N}_{\infty}\left(\frac{\mathrm{I}}{n_{1}{ }^{2}}+\frac{\mathrm{I}}{n_{2}{ }^{2}}-\frac{\mathrm{I}}{m_{1}{ }^{2}}-\frac{\mathrm{I}}{m_{2}{ }^{2}}\right) .
$$

These frequencies were then sought for in the secondary spectrum of hydrogen; it is known that negatively charged atoms are to be found in hydrogen at fairly high pressures with intensity quite comparable with that of the positively charged atom ("Rays of Positive Electricity," p. 39). As a result it was found that 47 lines in the secondary spectrum agreed with the calculated values within an absolute error of one unit of frequency, taking integral values of $n_{2}$ and $m_{1}$ from $\mathrm{I}$ up to IO, and values of $m_{2}$ from I to $x_{5}$, while $n_{1}$ was taken as 2 and 3 .

This means that the frequencies can be looked on as a kind of "summation tone," being the sums of a Balmer or a Paschen frequency and a frequency in the infra-red.

It was also found that in several cases a physical similarity of behaviour was common to "series" of the lines grouped according to the $m$ 's and n's concerned, though this was not exclusively true. As a standard of reference for the observed frequencies the values obtained by Merton and Barratt (Phil. Trans. A, I922, pp. 388-400) were employed.

\begin{tabular}{|c|c|c|c|c|c|}
\hline$\frac{3 \cdot 9}{2 \cdot 6}$ & 16934.9 & $16934.5 \mathrm{I}$ & +0.39 & $2++\mathrm{CD}$ & \\
\hline$\frac{3 \cdot 10}{2 \cdot 6}$ & $17192 \cdot 3$ & I7I92.I4 & +0.16 & $6++\mathrm{CD}++\mathrm{H}$ & $\mathrm{P}+\mathrm{He}$ \\
\hline$\frac{3 \cdot 12}{2 \cdot 6}$ & $17527 \cdot 6$ & $17527 \cdot 47$ & +0.13 & $3++\mathrm{CD}+\mathrm{HP}$ & $++\mathrm{He}$ \\
\hline $\begin{array}{l}3 \cdot 13 \\
2 \cdot 6\end{array}$ & ${ }^{17} 76_{3} 8.8$ & 17639.89 & $-r \cdot 09$ & $\mathrm{O}++\mathrm{CD}$ & $++\mathrm{He}$ \\
\hline$\frac{6 \cdot 6}{3 \cdot 3}$ & 18289.8 & I 8288.26 & +0.54 & o & \\
\hline$\frac{6 \cdot 8}{3 \cdot 3}$ & 19623.4 & $\mathrm{r} 9622 \cdot 74$ & +0.66 & $\mathrm{o}+\mathrm{He}$ & \\
\hline $6 \cdot 1$ & $20240 \cdot 7$ & $20240 \cdot 7 x$ & -0.01 & $+\mathrm{LP}$ & \\
\hline
\end{tabular}

As typical may be given the following :-

Formula. Calculated. Observed. Error $d v$. Character.

In the foregoing table, the figures in the last column refer to intensity and the symbols to the physical properties of the lines as given by Merton and Barratt (loc. cit.).

It is hoped to complete these and similar calculations shortly and also to investigate the conditions under which these lines should be enhanced.

A. C. Menzies.

Physics Laboratory, The University, Leeds, December 8.

\section{Science and the Empire.}

ThE admirable sentiments expressed in the leading article in NATURE. of December 16 will undoubtedly be re-echoed by every scientific worker in the country. In stating, however, that the British Science Guild is the only organisation which exists to undertake the propaganda work "for the extension of an understanding of the influence of scientific research and its results," the very effective propaganda which is being carried out by scientific workers themselves under the 